\title{
Determination of P-Glycoprotein ATPase Activity Using Luciferase
}

\author{
Tamihide Matsunaga, ${ }^{a}$ Eiji Kose, ${ }^{a}$ Sachiyo Yasuda, ${ }^{a}$ Hirohiko Ise,,${ }^{b}$ Uichi Ikeda,,${ }^{b}$ and \\ Shigeru OHMORI ${ }^{*, a}$
}

${ }^{a}$ Division of Pharmacy, Shinshu University Hospital; 3-1-1 Asahi, Matsumoto 390-8621, Japan: and ${ }^{b}$ Department of Organ Regeneration, Institute of Organ Transplants, Reconstructive Medicine and Tissue Engineering, Shinshu University Graduate School of Medicine; 3-1-1 Asahi, Matsumoto 390-8621, Japan.

Received August 19, 2005; accepted November 25, 2005

We investigated whether P-glycoprotein (P-gp) ATPase activity of Caco-2 cell membranes could be estimated by measuring consumption of ATP using luciferin-luciferase reaction, and whether the results would be useful for assessment of the interactions between P-gp and drugs. The vanadate-sensitive ATPase activity of Caco-2 cell membranes was measured rapidly with high sensitivity using luciferin-luciferase reaction. $\mathrm{Cy}$ closporin A, verapamil, digoxin and quinidine stimulated the ATPase activity concentration-dependently with $K_{\mathrm{m}}$ values of 5.3, 0.9, 1.2 and $4.1 \mu \mathrm{M}$, respectively. These values except for digoxin were comparable with previous reports. The ATPase activity and P-gp mRNA expression in Caco-2 cells were induced by all-trans-retinoic acid, digoxin and levothyroxine, but not dexamethasone or rifampicin. This method was useful to assess interactions with P-gp and drugs, and was used to elucidate the mechanisms of interaction of levothyroxine and digoxin.

Key words P-glycoprotein; ATPase; luciferine-luciferase reaction; Caco-2 cell; levothyroxine; digoxin

P-glycoprotein (P-gp), the product of the multidrug resistance 1 (MDRl) gene, is one of the most important members of the ATP-binding cassette (ABC) transporter family of membrane proteins that utilises the energy of ATP hydrolysis to exclude hydrophobic compounds from cells. P-gp is expressed constitutively in many normal tissues besides tumour cells, including the intestinal epithelium, blood-brain barrier endothelium, hepatocytes and renal tubular cells, ${ }^{1,2}$ and plays important roles in drug absorption, elimination and distribution. ${ }^{3)}$ A large number of drugs have been identified as substrates, inhibitors or inducers of P-gp. Intestinal expression of P-gp may affect the oral bioavailability of drug molecules that are substrates for this transporter. That is, P-gp regulates the intestinal absorption of drugs, such as digoxin, talinolol and cyclosporin, after oral dosing, and excretes paclitaxel into the intestine. ${ }^{4-7)}$

A variety of in vitro assays have been used to classify compounds as substrates, inhibitors or inducers of P-gp. ${ }^{8-14)}$ The monolayer efflux assay is the standard for identifying Pgp substrates because this assay measures efflux in the most direct manner. ${ }^{8)}$ Monolayer efflux assays, however, are labour-intensive due to cell culture and analytical requirements, which limited assay throughput. On the other hand, the P-gp ATPase assay is a valuable screening tool for determining if a drug interacts with P-gp, although this method does not measure transport directly. ${ }^{9-12)}$ Adachi et al. ${ }^{15)}$ concluded from comparative studies on in vitro methods for evaluating the in vivo function of P-gp that the extent of ATP-hydrolysis in vitro may also be a useful parameter for in vivo prediction, particularly for eliminating P-gp substrates in high-throughput screening procedures.

The inorganic phosphate released by P-gp ATPase in the presence of drugs is generally quantified by colourimetric assay. ${ }^{9-12)}$ When ATP is the limiting component in the luciferin-luciferase reaction, the intensity of the emitted light is proportional to the concentration of ATP. Measurement of the light intensity using a luminometer permits direct quantification of ATP. ${ }^{16,17)}$ Quantification of ATP by luciferin-luciferase reaction is extremely simple and high sensitive.
Alterations in the sensitivity of patients with thyroid disorders to digoxin have been recognised for many years. Frye and Braunwald ${ }^{18)}$ demonstrated that higher doses of digitalis were necessary to control the ventricular rates of patients with hyperthyroidism and atrial fibrillation. This phenomenon has been attributed to the lower plasma concentrations of digoxin in hyperthyroidism. The changes in the expression and function of duodenal P-gp were generally associated with alterations in the absorption of digoxin after oral administration. Siegmund et al. reported that P-gp mRNA expression and immunoreactive P-gp in the duodenums of healthy volunteers were increased after administration of levothyroxine. ${ }^{19)}$

Although obtained from human colorectal cancer, the Caco-2 cell line is capable of morphological and biochemical differentiation in vitro to form intestinal epithelia under normal culture conditions. ${ }^{20)}$ Transcript levels of ABC transporters except for breast cancer-related protein (BCRP) show a good correlation between jejunum and Caco-2 cells. ${ }^{21)}$ Caco-2 cells are thus widely accepted as the most useful in vitro model for rapid screening of intestinal drug absorption. ${ }^{22)}$

In the present study, we investigated whether the ATPase activity of the Caco- 2 cell membrane could be estimated by measuring consumption of ATP, and whether the results would be useful for assessment of the interactions between P-gp and drugs. Furthermore, we investigated the mechanisms of the interaction of levothyroxine and digoxin.

\section{MATERIALS AND METHODS}

Materials Verapamil, digoxin and all-trans-retinoic acid were purchased from Sigma Chemical Co. (St. Louis, MO, U.S.A.). TRIzol reagent and SuperScript First-Strand Synthesis System for reverse transcription-polymerase chain reaction (RT-PCR) were from Invitrogen Co. (Carlsbad, CA, U.S.A.). Dexamethasone, rifampicin, levothyroxine, quinidine and cyclosporin A were from Wako Pure Chemicals (Osaka, Japan). DC Protein Assay Kit was from Bio-Rad 
(Hercules, CA, U.S.A.). Caco-2 cells were obtained from Riken Cell Bank (Tsukuba, Japan). All other reagents used were of the highest quality available.

Cell Culture and Drug Treatment Caco- 2 cells were seeded on dishes coated with type I collagen and cultured in Dulbecco's modified Eagle medium supplemented with $2 \mathrm{~mm}$ glutamine, $10 \%(\mathrm{v} / \mathrm{v})$ foetal bovine serum and antibiotics under an atmosphere of $5 \% \mathrm{CO}_{2}$ at $37^{\circ} \mathrm{C}$. In the drug-treatment groups, the cells were cultured for $3 \mathrm{~d}$ after seeding of $5 \times 10^{5}$ cells $/ \mathrm{cm}^{2}$ in 6 -well culture plates and were treated with all-trans-retinoic acid $(10 \mu \mathrm{M})$, dexamethasone $(10 \mu \mathrm{M})$ or rifampicin $(10 \mu \mathrm{M})$ for $48 \mathrm{~h}$, or digoxin $(1 \mu \mathrm{M})$ or levothyroxine $(10 \mu \mathrm{M})$ for $24 \mathrm{~h}$. The above compounds were dissolved in dimethyl sulfoxide (DMSO), which was added to the culture medium at a final concentration of $0.1 \%$.

Membrane Vesicle Preparation Plasma membrane vesicles were prepared from Caco-2 cells as described ${ }^{23)}$ with modifications. The membrane pellet was resuspended in 50 $\mathrm{mm}$ Tris $-\mathrm{HCl}$ ( $\mathrm{pH} 7.4$ ) containing $250 \mathrm{~mm}$ sucrose and passed 10 times through a 27 -gauge needle for vesicle formation. The aliquot suspensions were stored at $-80^{\circ} \mathrm{C}$ until use.

Determination of P-gp ATPase Activity Using Luciferase The abilities of compounds to stimulate ATP hydrolysis were examined using the membrane vesicles prepared from Caco- 2 cells. Aliquots of $20 \mu \mathrm{g}$ protein from membrane vesicles were incubated in $60 \mu \mathrm{l}$ of medium consisting of $50 \mathrm{~mm}$ 2-morpholinoethanesulfonic acid, $50 \mathrm{~mm}$ $\mathrm{KCl}, 2 \mathrm{~mm}$ dithiothreitol, $2 \mathrm{~mm}$ ethyleneglycol bis (2aminoethyl ether)-tetraacetic acid, $5 \mathrm{~mm}$ sodium azide, $2 \mathrm{~mm}$ Tris- $\mathrm{HCl}$ (pH 6.8) and Mg-ATP with or without test compounds for $3 \mathrm{~min}$ at $37^{\circ} \mathrm{C}$. An identical reaction mixture containing $75 \mu \mathrm{M}$ sodium orthovanadate was assayed in parallel. Orthovanadate inhibits P-gp by trapping Mg-ADP in the nucleotide binding site upon incubation with orthovanadate and ATP $^{24)}$ Vanadate-sensitive ATP hydrolysis was determined by subtracting the value obtained with the sodium orthovanadate co-incubated membrane fraction from the vanadate-free membrane fraction. The reaction was initiated by addition of Mg-ATP ( 5 pmol) and terminated by addition of $15 \mu \mathrm{l}$ of luciferin-luciferase solution for ATP assay. Residual Mg-ATP contents were determined using an Enliten ATP Assay System (Promega, Madison, WI, U.S.A.), which is designed to measure $10^{-11}$ to $10^{-16} \mathrm{~mol}$ of ATP. The relative light unit value was determined immediately after addition of luciferin-luciferase solution using Mini Lumat LB9506 (Berthold Japan, Tokyo, Japan). The calibration curves for Mg-ATP were linear from 0.5 to 6 pmol. The test compounds, i.e., digoxin and verapamil, and sodium orthovanadate did not affect the luciferin-luciferase reaction at concentrations up to 40 and $150 \mu \mathrm{M}$, respectively (data not shown). In the absence of test compounds, two additional reaction mixtures with or without orthovanadate were also assayed in parallel to determine substrate-stimulated vanadate-sensitive ATPase activity.

RNA Extraction and Semiquantitative RT-PCR Analysis Total RNA was extracted from the treated cells with TRIzol reagent. First-strand cDNA was generated from $2 \mu \mathrm{g}$ of total RNA. Reverse-transcription reaction was performed using SuperScript First-Strand Synthesis System for RT-PCR according to the manufacturer's instructions (Invitrogen).
With the cDNA thus obtained, PCR was carried out using the following oligonucleotide primers: sense primer $5^{\prime}-\mathrm{GA}$ GGTGAAGAAGGGCCAGACG-3'，P-gp ${ }^{25)}$; 5'-GGACCTGGACTTCGTTCTCA-3', multidrug resistance-associated protein 1 (MRP1 $)^{26)}$; 5'-CTGCCTCTTCAGAATCTTAG-3', MRP2 ${ }^{26)} ; 5^{\prime}$-CATCACCATCTTCCAGGAGC-3', glyceraldehyde-3-phosphate dehydrogenase (GAPDH) and antisense primer 5'-TTCTGGATGGTGGACAGGCGG-3', P-gp; 5' CGTCCAGACTTCTTCATCCG-3', MRP1 ${ }^{26)}$; 5'-ATAACCCAAGTTGCAGGCT-3', MRP2 ${ }^{26)}$; 5'-CATGAGTCCTTCCACGATACC-3', GAPDH. The levels of these mRNAs were quantified from the band density on agarose gels using Printgraph AE-6914 and Scion Image Software (by Dr. W. Rasband), and were normalised relative to that of GAPDH mRNA.

Statistical Analysis Statistical comparisons were performed with Student's $t$-test.

Other Methods Protein concentration was estimated using a DC Protein Assay Kit according to the manufacturer's instructions, using bovine serum albumin as a standard.

\section{RESULTS}

Analysis of P-gp ATPase Activity Using Luciferase ATPase activity stimulated with verapamil, which is a wellknown P-gp substrate, was increased in a protein concentration- and incubation time-dependent manner. The activity increased linearly with protein concentration up to $20 \mu \mathrm{g}$ per incubation mixture and until an incubation time of $3 \mathrm{~min}$. Therefore, in the stimulation of ATP hydrolysis, the Caco-2 cell membrane vesicles $(20 \mu \mathrm{g})$ and Mg-ATP $(5 \mathrm{pmol})$ were incubated with or without test compounds in the presence and absence of sodium orthovanadate $(75 \mu \mathrm{M})$ for $3 \mathrm{~min}$ at $37^{\circ} \mathrm{C}$.

To evaluate the simple method of determining P-gp ATPase activity using luciferase, we examined the stimulatory effects of cyclosporin A, verapamil, digoxin and quinidine, which are typical substrates of P-gp, on ATPase activity in Caco-2 cell membrane vesicles. These test compounds stimulated P-gp ATPase activity in a concentration-dependent manner. Cyclosporin A, verapamil, digoxin and quinidine showed maximal stimulation at $20,5,5-10$ and $10 \mu \mathrm{M}$, respectively. Kinetic parameters for P-gp ATPase activity were analyzed according to the Michaelis-Menten equation to determine the apparent $V_{\max }$ and $K_{\mathrm{m}}$ values (Fig. 1). The $K_{\mathrm{m}}$ and $V_{\max }$ values of cyclosporin A, verapamil, digoxin and quinidine were estimated to be $5.3,0.9,1.2$ and $4.1 \mu \mathrm{M}$, and 11.5 , $10.1,10.2$ and $12.3 \mathrm{pmol} / \mathrm{min} / \mathrm{mg}$ protein, respectively.

mRNA Expression and P-gp ATPase Activity in Caco-2 Cells Treated with Various Drugs We investigated the effects of treatment with various drugs on P-gp mRNA expression and P-gp ATPase activity in Caco-2 cells. As shown in Fig. 2, P-gp mRNA expression was increased by 3.4- and 4.6-fold as compared with the control by all-trans-retinoic acid and digoxin, respectively. However, dexamethasone and rifampicin, ligands of pregnane $\mathrm{X}$ receptor (PXR), did not induce P-gp mRNA expression. MRP1 mRNA expression was relatively suppressed by all-trans-retinoic acid, although it was increased by about 4-fold as compared with the control by digoxin. MRP2 mRNA expression level showed no signif- 
A

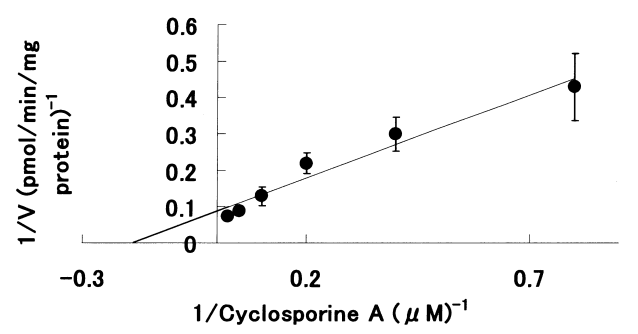

C

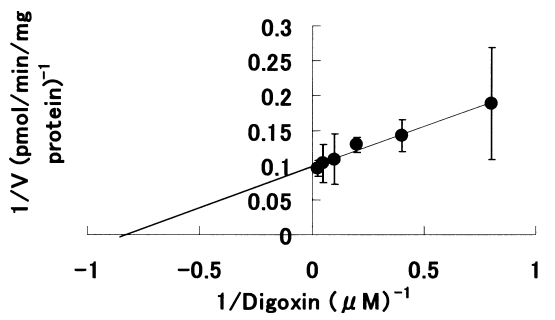

B

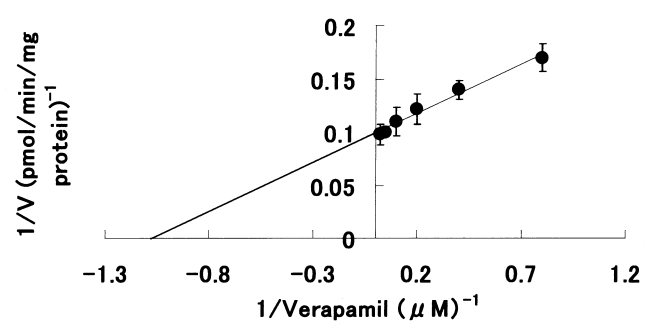

D

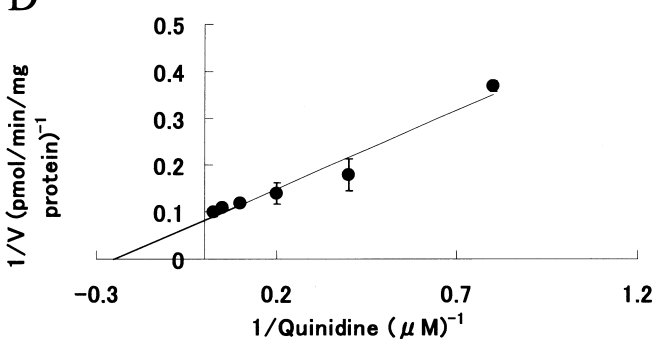

Fig. 1. Kinetic Analyses of the Orthovanadate Sensitive P-gp ATPase Activity Stimulated by Cyclosporin A (A), Verapamil (B), Digoxin (C), or Quinidine (D)

Values are expressed as the mean \pm S.E. of three experiments. Each test compound was incubated with Mg-ATP (5.0 pmol) and Caco- 2 cell membrane vesicles ( $20 \mu \mathrm{g})$ in the presence or absence of orthovanadate $(75 \mu \mathrm{M})$ at $37^{\circ} \mathrm{C}$ for $3 \mathrm{~min}$.

A
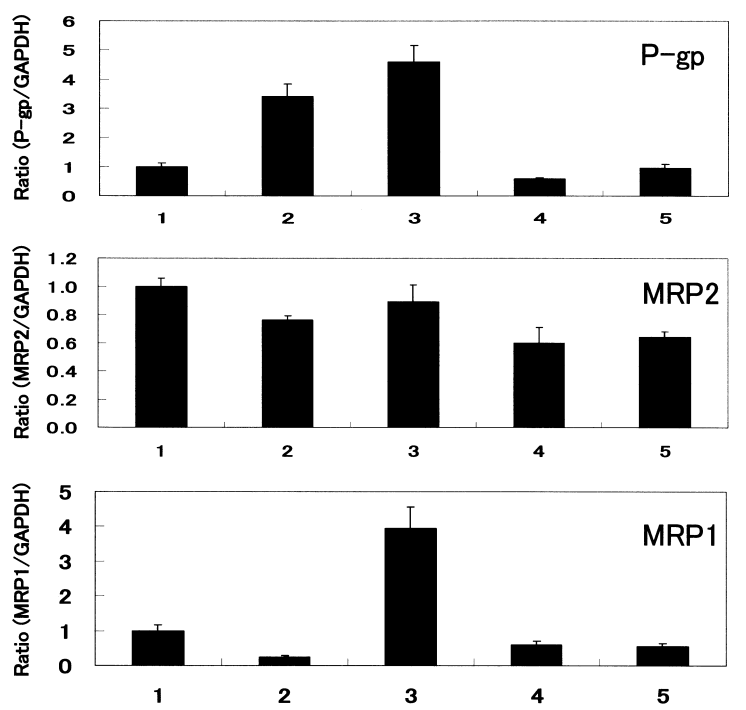

B

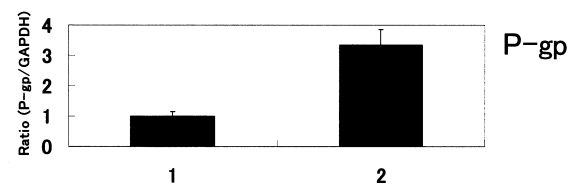

Fig. 2. Effects of All-trans-Retinoic Acid, Digoxin, Dexamethasone, Rifampicin and Levothyroxine on Expression of P-gp mRNA in Caco-2 Cells

Caco- 2 cells were treated with $10 \mu \mathrm{M}$ of all-trans-retinoic acid, dexamethasone or rifampicin for $48 \mathrm{~h}, 10 \mu \mathrm{M}$ of levothyroxine for $24 \mathrm{~h}$, or $1 \mu \mathrm{M}$ of digoxin for $24 \mathrm{~h}$. The compounds were dissolved in DMSO, which was added to the culture medium at a final concentration of $0.1 \%$. After treatment, mRNA was analyzed by semiquantitative RTPCR as described in Materials and Methods. (A), Data presented are the ratio of P-gp, MRP1, or MRP2 to GAPDH and normalized at 1.0 for DMSO treatment alone. 1, DMSO; 2, all-trans-retinoic acid; 3, digoxin; 4, dexamethasone; 5, rifampicin. (B), Data presented are the ratio of P-gp to GAPDH and normalized at 1.0 for DMSO treatment alone. 1, DMSO; 2, levothyroxine. Values are expressed as the mean \pm S.E. of three experiments.

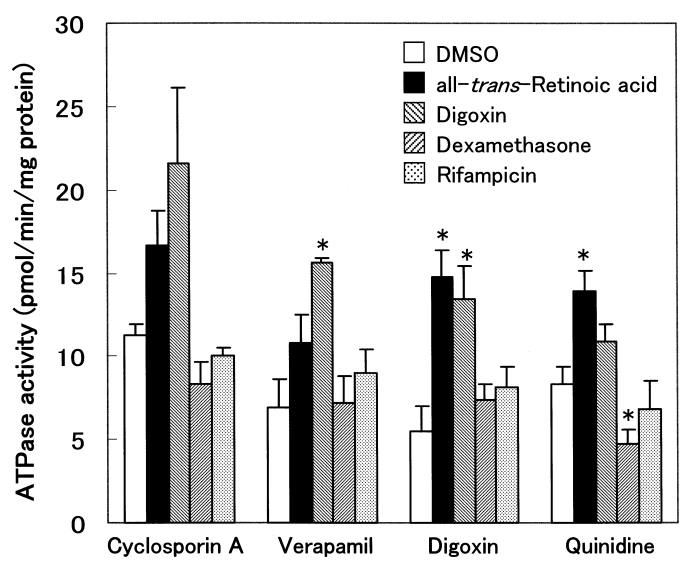

Fig. 3. Effects of All-trans-Retinoic Acid, Digoxin, Dexamethasone and Rifampicin on P-gp ATPase Activity in Caco-2 Cells

Caco- 2 cells were treated with all-trans-retinoic acid $(10 \mu \mathrm{M})$, dexamethasone $(10$ $\mu \mathrm{M})$ or rifampicin $(10 \mu \mathrm{M})$ for $48 \mathrm{~h}$, or digoxin $(1 \mu \mathrm{M})$ for $24 \mathrm{~h}$. These compounds were dissolved in DMSO, which was added to the culture medium at a final concentration of $0.1 \%$. ATPase activity was determined as described in Materials and Methods. The concentration of cyclosporin A, verapamil, digoxin and quinidine was $20 \mu \mathrm{M}$. Values are expressed as the mean \pm S.E. of three experiments. $*$ Significantly different from DMSO group $(p<0.05)$.

icant changes following addition of the inducers used in this study.

P-gp ATPase activity stimulated by cyclosporin A, verapamil, digoxin or quinidine was induced to about 2-fold as compared with the control by treatment with all-transretinoic acid and digoxin (Fig. 3). However, ATPase activity was not induced by treatment with dexamethasone and rifampicin.

Effects of Levothyroxine on P-gp mRNA Expression and P-gp ATPase Activity in Caco-2 Cells Frye and Braunwald reported that thyroid function alters the pharmacokinetics of digoxin. ${ }^{18)}$ Absorption of digoxin in humans is related to the expression and function of duodenal P-gp, which is modified by drug interactions. ${ }^{27)}$ To evaluate the 


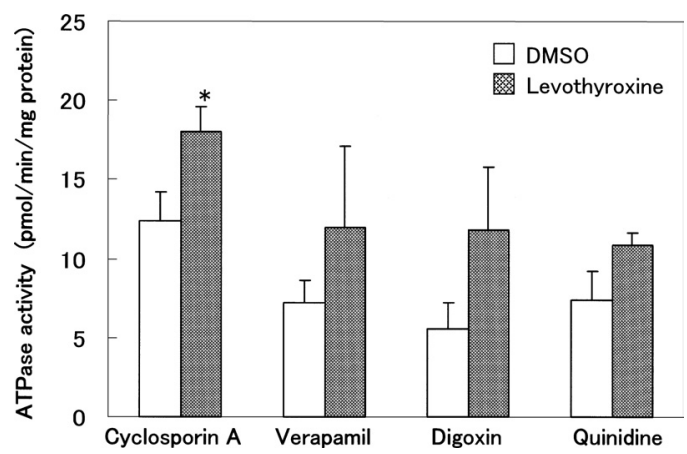

Fig. 4. Effects of Levothyroxine on P-gp ATPase Activity in Caco-2 Cells

Caco-2 cells were treated with levothyroxine $(10 \mu \mathrm{M})$ for $24 \mathrm{~h}$. Levothyroxine was dissolved in DMSO, which was added to the culture medium at a final concentration of $0.1 \%$. ATPase activity was determined as described in Materials and Methods. The concentration of cyclosporin A, verapamil, digoxin and quinidine was $20 \mu \mathrm{M}$. Values are expressed as the mean \pm S.E. of three experiments. * Significantly different from DMSO group $(p<0.05)$.

participation of P-gp in the drug interactions of digoxin and levothyroxine, we investigated the effects of levothyroxine on the expression of P-gp in Caco-2 cells. Caco-2 cells were treated with $10 \mu \mathrm{M}$ levothyroxine for $24 \mathrm{~h}$. Levothyroxine upregulated P-gp mRNA expression in Caco-2 cells by 3.4-fold as compared with controls (Fig. 2). P-gp ATPase activity with addition of cyclosporin A, verapamil, digoxin or quinidine was induced to 1.5-, 1.7-, 2.1- and 1.5-fold, respectively, as compared with controls by treatment with levothyroxine (Fig. 4).

\section{DISCUSSION}

In the present study, we investigated whether the ATPase activity and its kinetic parameters of the Caco-2 cell membranes could be estimated by measuring consumption of ATP. Experiments were initiated by addition of Mg-ATP. After incubation, the residual Mg-ATP contents could be measured immediately by the ATP assay system using the luciferin-luciferase reaction that was designed to measure $10^{-11}$ to $10^{-16} \mathrm{~mol}$ of ATP. The measurement time of the light intensity was only 5 to $10 \mathrm{~s}$ after addition of the reagents. Orthovanadate inhibits P-gp by trapping Mg-ADP in the nucleotide binding site. ${ }^{24)}$ Thus, ATPase activity measured in the presence of orthovanadate represents non-P-gp ATPase activity and can be subtracted from the activity generated without orthovanadate to yield vanadate-sensitive ATPase activity. The activation ratio refers to changes in Pgp-specific Mg-ATP consumption by membranes incubated with and without the test drug.

To establish an ATPase stimulation pattern that is characteristic to P-gp, the abilities of various drugs known to modulate its ATPase activity were examined by the method using the luciferin-luciferase reaction. The testing of multiple drug concentrations allowed estimation of the affinity of the drug for P-gp and whether saturation of the response was observed. ATPase activity in the plasma membranes was stimulated in a concentration-dependent manner by cyclosporin A, verapamil, digoxin and quinidine. The kinetic parameters were compared with values reported previously, which were determined by colourimetric assay of inorganic phosphate. Adachi et al. ${ }^{15)}$ reported that the $K_{\mathrm{m}}$ values of cyclosporin A, verapamil, digoxin and quinidine were $0.17,4.06,25.9$ and
$5.42 \mu \mathrm{M}$, respectively, in the membrane fraction from High Five (BTI-TN5B1-4) cells expressing P-gp. However, Rebbeor et al. ${ }^{28)}$ reported that both verapamil and quinidine showed maximal stimulation at $10 \mu \mathrm{m}$ in both plasma membranes containing 30\% P-gp, measured as a percentage of total membrane protein, and a reconstituted system of purified P-gp. Further, they also reported that the concentration required for half-maximal stimulation of verapamil and quinidine was $1 \mu \mathrm{m} .{ }^{28)}$ Borgnia et al. ${ }^{29)}$ also reported that verapamil and quinidine stimulated the ATPase activity by 1.8and 1.3 -fold with apparent $K_{\mathrm{m}}$ values of 2 and $10 \mu \mathrm{M}$, respectively. Sarkadi et al. ${ }^{11)}$ estimated the concentrations of verapamil and quinine (a stereoisomer of quinidine) required for half-maximal activation of the vanadate-sensitive ATPase activity in isolated membranes of P-gp baculovirus-infected Sf9 cells to be 0.5 and $3 \mu \mathrm{M}$, respectively. Ramachandra et $a .^{30)}$ also reported that the $K_{\mathrm{m}}$ value of verapamil was $2.9 \mu \mathrm{M}$ when using a reconstituted system of purified P-gp. Furthermore, Saeki et $_{\text {al. }}{ }^{31)}$ reported that the $K_{\mathrm{m}}$ value for the transcellular transport of cyclosporin A was $8.4 \mu \mathrm{M}$. In conclusion, the $K_{\mathrm{m}}$ values for cyclosporin A, verapamil and quinidine estimated by the method using the luciferin-luciferase reaction were comparable with previous reports. ${ }^{15,28-31)}$ However, we do not know why the $K_{\mathrm{m}}$ value for digoxin is very different from previous report. ${ }^{15)}$ It might be caused by contribution of other transporters due to the use of membranes of Caco-2 cells in the present study. On the other hand, the $V_{\max }$ values of cyclosporin A, verapamil, digoxin and quinidine were markedly lower than those of these compounds reported previously. ${ }^{1528-32)}$ The reason why the $V_{\max }$ values were low may be attributable to the use of extremely low concentrations of Mg-ATP, because P-gp ATPase activity is increased by Mg-ATP in a concentration-dependent manner. ${ }^{33)}$ Furthermore, the data reported previously were measured by using the cell membranes overexpressing P-gp or a reconstituted system of purified P-gp as described above, ${ }^{11,15,28-32)}$ while we used membranes prepared from Caco- 2 cells.

Thyroid function alters the pharmacokinetics of digoxin. ${ }^{18)}$ In general, the changes in the expression and function of duodenal P-gp were associated with alterations in the absorption of digoxin after oral administration. We hypothesised that thyroid hormones were involved directly in the regulation of P-gp expression, because the alterations in the pharmacokinetics of digoxin and other drugs in patients with hyperthyroidism could be explained by induction of P-gp. In the present study, Caco- 2 cells were cultured for $24 \mathrm{~h}$ in the presence of $10 \mu \mathrm{M}$ levothyroxine to investigate whether the drug induces human P-gp in vitro. P-gp mRNA expression and P-gp ATPase activity were enhanced by treatment with levothyroxine. hPXR is a key regulator of both $C Y P 3 A 4$ and MDRI $(P-g p){ }^{34)}$ hPXR mRNA is absent or expressed at only extremely low levels in Caco-2 cells, because in a preliminary experiment, hPXR mRNA was not detected in Caco-2 cells by RT-PCR (data not shown). This result was consistent with the findings of another group, ${ }^{35)}$ who did not detect hPXR mRNA in Caco-2 cells. The absence of hPXR in Caco-2 cells helps explain the observed failure to induce Pgp after treatment with rifampicin and dexamethasone (Figs. $2,3)$. These results suggested that hPXR does not mediate levothyroxine induction of P-gp. 
The expression of P-gp and MRP1 mRNAs was markedly induced by digoxin (Fig. 2). The induction of P-gp in Caco-2 cells by digoxin was consistent with the results of Takara et $a l$. previously reported. ${ }^{36)}$ On the other hand, it may be the first time that the human MRP1 gene was found to be inducible in Caco- 2 cells by digoxin.

In the present study, we used Caco-2 cells to develop an assay for the rapid assessment of the interactions of drugs on P-gp. Caco-2 cells are the preferred physiological model for drug transport studies ${ }^{37)}$ as the ABC-transporters, P-gp and MRP1-MRP5, showed similar expression patterns in Caco-2 cells as in human jejunal biopsies. P-gp exhibits partial substrate overlap with other $\mathrm{ABC}$ transporters, such as BCRP and MRP2. The potential contribution of BCRP and MRP2 to the results of the present study is less clear. The expression level of BCRP in Caco-2 monolayers is extreamly low. ${ }^{21)}$ Furthermore, the ATPase activity was induced by all-transretinoic acid and digoxin (Fig. 3), although the expression of MRP2 mRNA was not induced by these drugs (Fig. 2). On the other hand, the changes in ATPase activity in Caco-2 cells with drug treatments corresponded to those of P-gp mRNA expression. It is suggested that BCRP and MRP2 little contribute to the drug-stimulated vanadate-sensitive ATPase activity in the present conditions. However, the present results cannot broadly determine P-gp specific activity, or completely exclude the contribution of other efflux transporters to the results. It will be possible to evaluate P-gp ATPase activity both precisely and simply in this assay system using luciferin-luciferase reaction if purified P-gp or membranes of cells overexpressing P-gp by transformation are used.

Acknowledgments We thank Drs. Shigeyuki Kawa and Kendo Kiyosawa, Department of Medicine, Shinshu University School of Medicine, for support of luciferase assay. This work was partly supported by Grants-in-Aid from the Ministry of Education, Culture, Sports, and Science of Japan.

\section{REFERENCES}

1) Sugawara I., Kataoka I., Morishita Y., Hamada H., Tsuruo T., Itoyama S., Mori S., Cancer Res., 48, 1926-1929 (1988).

2) Cordon-Cardo C., O'Brien J. P., Casals D., Rittman-Grauer L., Biedler J. L., Melamed M. R., Bertino J. R., Proc. Natl. Acad. Sci. U.S.A., 86, 695-698 (1989)

3) Ambudkar A. V., Dey S., Hrycyna C. A., Ramachandra M., Pastan I., Gottesman M. M., Annu. Rev. Pharmacol. Toxicol., 39, 361-398 (1999).

4) Lown K. S., Mayo R. R., Leichtman A. B., Hsiao H. L., Turgeon D. K., Schmiedlin-Ren P., Brown M. B., Guo W., Rossi S. J., Benet L. Z., Watkins P. B., Clin. Pharmacol. Ther, 62, 248-260 (1997).

5) Sparreboom A., van Asperen J., Mayer U., Schinkel A. H., Smit J. W., Meijer D. K., Borst P., Nooijen W. J., Beijnen J. H., van Tellingen O., Proc. Natl. Acad. Sci. U.S.A., 94, 2031-2035 (1997).

6) Verschraagen M., Koks C. H., Schellens J. H., Beijnen J. H., Pharmacol. Res., 40, 301-306 (1999).

7) Schwarz U. I., Gramatte T., Krappweis J., Oertel R., Kirch W., Int. J.
Clin. Pharmacol. Ther, 38, 161-167 (2000)

8) Kim R. B., Fromm M. F., Wandel C., Leake B., Wood A. J., Roden D. M., Wilkinson G. R., J. Clin. Invest., 101, 289-294 (1998).

9) Scarborough G. A., J. Bioenerg. Biomembr., 27, 37-41 (1995).

10) Litman T., Zeuthen T., Skovsgaard T., Stein W. D., Biochim. Biophys. Acta, 1361, 159-168 (1997).

11) Sarkadi B., Price E. M., Boucher R. C., Germann U. A., Scarborough G. A., J. Biol. Chem., 267, $4854-4858$ (1992).

12) Onishi Y., Hirano H., Nakata K., Oosumi K., Nagakura M., Tarui S., Ishikawa T., Chem-Bio. Informatics J., 3, 175-193 (2003).

13) Liminga G., Nygren P., Larsson R., Exp. Cell Res., 212, 291-296 (1994).

14) Perloff M. D., Stormer E., von Moltke L. L., Greenblatt D. J., Pharm. Res., 20, 1177-1183 (2003).

15) Adachi Y., Suzuki H., Sugiyama Y., Pharm. Res., 18, 1660-1668 (2001).

16) McElroy W. D., Deluca M. A., J. Appl. Biochem., 5, 197-209 (1983).

17) Lundin A., Thore A., Anal. Biochem., 66, 47-63 (1975).

18) Frye R. L., Braunwald E., Circulation, 23, 376-382 (1961).

19) Siegmund W., Altmannsberger S., Paneitz A., Hecker U., Zschiesche M., Franke G., Meng W., Warzok R., Schroeder E., Sperker B., Terhaag B., Cascorbi I., Kroemer H. K., Clin. Pharmacol. Ther, 72, $256-264$ (2002)

20) Pinto M., Robine-Leon S., Appay M. D., Kedinger M., Triadou N., Dussaulx E., Lacroix B., Simon-Assmann P., Haffen K., Fogh J., Zweibaum A., Biol. Cell, 47, 323-330 (1983).

21) Taipalensuu J., Tornblom H., Lindberg G., Einarsson C., Sjoqvist F., Melhus H., Garberg P., Sjostrom B., Lundgren B., Artursson P., J. Pharmacol. Exp. Ther., 299, 164-170 (2001).

22) Boulenc X., S. T. P. Pharm. Sci., 72, 259-269 (1997).

23) Loe D. W., Almquist K. C., Deeley R. G., Cole S. P. C., J. Biol. Chem., 271, 9675-9682 (1996).

24) Urbatsch I. L., Tyndall G. A., Tombline G., Senior A. E., J. Biol. Chem., 278, 23171-23179 (2003).

25) Arima H., Yunomae K., Hirayama F., Uekawa K., J. Pharmacol. Exp. Ther, 297, 547-555 (2001)

26) Decleves X., Fajac A., Lehmann-Che J., Tardy M., Mercter C., Hurbain T., Laplanche J. L., Bernaudin J. F., Scherrmann J. M., Int. J. Cancer, 98, 173-180 (2002).

27) Zhou S., Lim L. Y., Chowbay B., Drug Metab. Rev., 36, 57-104 (2004).

28) Rebbeor F. J., Senior A. E., Biochim. Biophys. Acta, 1369, 85-93 (1998).

29) Borgnia M. J., Eytan G. D., Assaraf Y. G., J. Biol. Chem., 271, $3163-$ 3171 (1996).

30) Ramachandra M., Ambudkar S. V., Chen D., Hrycyna C. A., Dey S., Gottesman M. M., Pastan I., Biochemistry, 37, 5010-5019 (1998).

31) Saeki T., Ueda K., Tanigawara Y., Hori R., Komano T., J. Biol. Chem., 268, 6077-6080 (1992).

32) Schwab D., Fischer H., Tabatabaei A., Poli S., Huwyler J., J. Med. Chem., 46, 1716-1725 (2003).

33) Muller M., Bakos E., Welker E., Varadi A., Germann U. A., Gottesman M. M., Morse B. S., Roninson I. B., Sarkadi B., J. Biol. Chem., 271, 1877-1883 (1996).

34) Sahi J., Milad M. A., Zheng X., Rose K. A., Wang H., Stilgenbauer L., Gilbert D., Jolley S., Stern R. H., LeCluyse E. L., J. Pharm. Exp. Ther, 306, 1027-1034 (2003).

35) Thummel K. E., Brimer C., Yasuda K., Thottassery J., Senn T., Lin Y., Ishizuka H., Kharasch E., Schuetz J., Schuetz E., Mol. Pharmacol., 60, 1399-1406 (2001).

36) Takara K., Tsujimoto M., Ohnishi N., Yokoyama T., Biochem. Biophys. Res. Commun., 292, 190-194 (2002).

37) Pfrunder A., Gutmann H., Beglinger C., Drewe J., J. Pharm. Pharmacol., 55, 59-66 (2003). 